\title{
Cost-Benefit Analysis for the Concentrated Solar Power in China
}

\author{
Shuxia Yang $(\mathbb{D}$, Xianguo Zhu, and Weishang Guo $\mathbb{1}$ \\ School of Economics and Management, North China Electric Power University, Beijing 102206, China \\ Correspondence should be addressed to Weishang Guo; 547180981@qq.com \\ Received 4 January 2018; Revised 4 March 2018; Accepted 29 March 2018; Published 14 May 2018 \\ Academic Editor: Gorazd Stumberger
}

Copyright (C) 2018 Shuxia Yang et al. This is an open access article distributed under the Creative Commons Attribution License, which permits unrestricted use, distribution, and reproduction in any medium, provided the original work is properly cited.

\begin{abstract}
In 2016, the first batch of concentrated solar power (CSP) demonstration projects of China was formally approved. Due to the important impact of the cost-benefit on the investment decisions and policy-making, this paper adopted the static payback period (SP), net present value (NPV), net present value rate (NPVR), and internal rate of return (IRR) to analyze and discuss the costbenefit of CSP demonstration plants. The results showed the following. (1) The SP of CSP systems is relatively longer, due to high initial investment; but the cost-benefit of CSP demonstration plants as a whole is better, because of good expected incomes. (2) Vast majority of CSP projects could gain excess returns, on the basis of meeting the profitability required by the benchmark yield of $10 \%$. (3) The cost-benefit of solar tower CSP technology (IRR of 12.33\%) is better than that of parabolic trough CSP technology (IRR of $11.72 \%$ ) and linear Fresnel CSP technology (IRR of 11.43\%). (4) The annual electricity production and initial costs have significant impacts on the cost-benefit of CSP systems; the effects of operation and maintenance costs and loan interest rate on the cost-benefit of CSP systems are relatively smaller but cannot be ignored.
\end{abstract}

\section{Introduction}

1.1. Background. Concentrating solar power (CSP) is an important solar energy generation power technology that has attracted increasing attention in many countries. Spain, America, South Africa, India, Morocco, Italy, Greece, Portugal, and others have issued a series of policies to promote the development of the CSP industry. At present, only the CSP plants in Spain and the United States realized commercial operation. The cumulative installations of both plants were about $4,079 \mathrm{MW}$ in 2016 , accounting for more than $80 \%$ of the global total installed capacity. However, the growth of new installed capacity of CSP in the United States and Spain started to slow down since 2015, due to the cancellation of preferential policies. The CSP industry is still in the early commercialization demonstration stage in some countries and even in the initial stage in other countries. But those countries have ambitious plans for the CSP development. For example, South Africa and Morocco were to install, respectively, 3.3 GW and 2 GW CSP plants by 2022 and Saudi Arabia planned to install $25 \mathrm{GW}$ CSP projects by 2040 .

As the world's largest carbon emission country, China has proposed ambitious emission reduction targets. In order to reduce the carbon emission effect of CSP, Chinese government began to pay great attention to the development of CSP industry. According to the 2050 solar roadmap of China [1], in order to achieve the large-scale commercialization operation, the development of CSP industry was divided into four stages, namely, the initial experimental stage (before 2015), demonstration phase (2015-2020), large-scale development phase (2020-2030), and large-scale commercial development stage (2030-2050). With the development of CSP, its role in the power system would change from the middle load of peak regulation to the power source of basic power load in the third stage. In recent years, China has made a series of policy reforms in order to create the CSP Roadmap plan. For example, in 2016, the CSP installations target of 2020 was set to $5 \mathrm{GW}$ in China's 13th Five-Year electric power plan. Notice on the benchmark feed-in tariff (FIT) policy of CSP was issued by National Development and Reform Commission (NDRC), and the on-grid price was determined to be RMB1.15/kWh (including tax) [2]. The first twenty CSP pilot plants have been approved officially by National Energy Administration (NEA) and the total installed capacity was 1,349 MW. The pilot projects of CSP will play an important demonstration effect for the development of CSP industry in 
China. Thus it can be expected that the CSP development will enter a rapid development stage in the future.

1.2. Literature Review. There are four available technologies for CSP, namely, parabolic trough (PT), linear Fresnel (LF), solar tower (ST), and parabolic dish (PD). The heat transfer fluids mainly include water, thermal oil, molten salt, all solid state concrete, and air. Over the past few decades, the thermal oil PT-CSP has been the most commercially attractive option among the existing CSP technologies and has widely been installed in the United States and Spain. STCSP technology has not been adopted widely in the existing CSP plants, but it has a better development potential because of the higher thermodynamic efficiency $[3,4]$. The high initial costs, which were estimated to vary between RMB27.73/W and RMB57.44/W (Exchange Rates on Dec. 19, 2017: \$1 = RMB6.602), have been obstructing the development of CSP [5]. However, with the advanced technology and the expansion of market scale, further reductions in the costs of CSP are expected in the future to finally reach a better power grid parity than the conventional fossil fuel power technologies [6,7].

Different from the photovoltaic (PV) power, CSP is able to effectively solve the issues on the instability and intermittency of solar energy by installing thermal energy storage (TES) systems. The application of TES is of significance for CSP development and it has been an important research direction in recent years. For example, Shinnar and Citro (2006) analyzed the prominent impact of TES on CSP systems [8]; Tian and Zhao (2013) provided a review for the latest improvement of the ETS applications [9]; Sioshansi and Denholm (2010) researched the profits obtained by CSP with TES in the electricity markets and concluded that TES has the potential to add to the values of CSP [10]; Madaeni et al. (2012) evaluated the cost-benefit of CSP plants with TES, and the installation of TES proved to be a reliable option [11]; International Renewable Energy Agency (2014) pointed out that CSP plants with TES usually required higher costs but improved the capacity factor of CSP system, resulting in lower levelized cost of energy (LCOE, the discounted uniform unit cost of energy in the whole life-cycle) [12]; REN 21 (2015) believed that TES has a large cost-reduction potential and provides a perfect opportunity to overcome the impediment of high initial investment for CSP plants [13]. The PV-CSP hybrid systems could also reduce the costs of CSP and improve both the reliability and efficiency of CSP systems [14-16]. Ju et al. (2017) held that PV-CSP hybrid system has several advantages compared to the PV-alone or CSP-alone systems [17]. Parrado et al. (2016) calculated the LCOE of PV-CSP hybrid plant based on the Blue Map scenario and Roadmap scenario. Between 2014 and 2050, the LCOE values obtained varied from RMB0.97/kWh to RMB0.57/kWh and from RMB0.92/kWh to RMB0.51/kWh [15]. Besides, there are many factors affecting the CSP costs. Caldés et al. (2009) concluded that the total costs of CSP mostly depended on TES capacity, labor costs, power plant size, and so on [5]. Izquierdo et al. (2010) studied the effects of solar multiple capacity factor and TES capacity on the costs of CSP [18]; Hernández-Moro and Martínez-Duart (2012) analyzed the main factors impacting the CSP costs, including cumulative installed capacity, electricity production, land cost, discount rate, operation and maintenance $(\mathrm{O} \& \mathrm{M})$ costs, insurance cost, and life-time [19].

In view of the importance of cost-benefit to the investment policy-making of power generation industry, the costbenefit analysis has been the research focus of energy electricity industry. About the solar power, it is divided into three types of power generation technologies, namely, PV power, solar chimney power plant (SCPP, one technology for the large-scale utilization of solar energy) [20], and CSP (the mechanism of a conventional SCPP is as follows [20]: sunlight transmits through the solar collector cover and heats the ground below; then ambient air enters the solar collector and is heated as it flows along the collector toward its centre, where a chimney is located; then the airflow enters the chimney, due to the pressure created by the density difference between the warm airflow and ambient cold air; finally, with the power conversion unit, the kinetic energy of the airflow is transferred into electrical power). PV power has achieved large-scale commercial development and its cost-benefit has been discussed widely in large numbers of literatures. For example, Zhao et al. (2015) calculated the static payback period (SP), net present value (NPV), and internal rate of return (IRR) of distributed PV plants and found that the cost-benefit of PV power varied widely in different regions, with IRR of about 7\%-21\% [21]; Yuan et al. (2014) adopted the LCOE to analyze the economy of the different scale distributed PV systems and concluded that their LCOE varied between RMB1.16/kWh and RMB1.29/kWh [22]. Solar chimney power plant (SCPP) is still in the early experiment stage, but some scholars have begun to focus on the cost-benefit of SCPP. For example, Li et al. (2014) analyzed the cost-benefit of reinforced concrete SCPP by calculating the total NPV of four different phases, with the total NPV rate of 0.390 , and held that it has very good application prospect in the future [23]; Guo et al. (2017) estimated the LCOE of the SCPP of RMB0.4178/kWh by taking a 10-MW SCPP of Yinchuan China as an example and concluded that the cost-benefit of SCPP could compete with the wind power and PV electricity [24]. CSP achieved the commercial development in Spain and in the United States but is still in commercialization demonstration stage in other countries. Studies on the cost-benefit of CSP mainly focus on the LCOE. According to Parrado et al. (2016), from 2014 to 2050, the LCOE of CSP decreased from RMB1.01/kWh to RMB0.60/kWh for the Blue Map scenario and was between RMB0.98/kWh and RMB0.50/kWh for the Roadmap scenario [15]; Hernández-Moro and MartínezDuart (2012) used the life-cycle cost method to discuss the LCOE of CSP in the period of 2010-2050 [19]. Zhu et al. (2015) found that the LCOE values of CSP in China varied between RMB1.2/kWh and RMB2.7/kWh [25], while Zhao et al. (2017) pointed out that the LCOE of SCP in China was approximately RMB1.44/kWh [26]. It can be seen that there were large numbers of investigations discussing the cost-benefit of SCP from the aspect of LCOE but they have not involved financial indexes such as SP, NPV, and IRR. Therefore, this study focused on calculating the static payback period (SP), the net present value (NPV), the net present 
value rate (NPVR), and the internal rate of return (IRR) of CSP and discussed the sensitivity factors of IRR, based on the first batch of CSP demonstration projects in order to analyze the cost-benefit of CSP in China comprehensively.

\section{Methodology}

This research used SP, NPV, NPVR, and IRR to study the cost-benefit of CSP in China. For CSP projects, the cash outflows $\left(\mathrm{CO}_{i}\right)$ include initial investment (II), operation and maintenance $(\mathrm{O} \& \mathrm{M})$ costs, insurance expenses, loan interest, and taxes costs. The cash inflows $\left(\mathrm{CI}_{i}\right)$ involve electricity generation incomes and government tax subsidies (namely, value-added tax (VAT) refund); that is,

$$
\begin{aligned}
& \mathrm{CO}_{i}= \begin{cases}\mathrm{II}_{i}, & i=1, \ldots, T_{0} \\
(\mathrm{OM}+I) C+R_{i}+\mathrm{TAX}_{i}, & i=T_{0}+1, \ldots, T\end{cases} \\
& \mathrm{CI}_{i}=\frac{\left(P \times E_{i}\right)(1-\alpha)}{\left(1+t_{\mathrm{VAT}}\right)}+\pi_{i}, \quad i=T_{0}+1, \ldots, T,
\end{aligned}
$$

where $T_{0}$ and $T$ are, respectively, construction period and life-time; $C$ represents the construction costs; $\mathrm{OM}$ is the ratio between annual O\&M costs and construction costs; $I$ represents the proportion of annual insurance expenses and construction costs; $R_{i}$ and $\operatorname{TAX}_{i}$ are, respectively, annual interest payments and annual taxes costs; $P$ and $E_{i}$ represent the on-grid price and annual electricity production, respectively; $\alpha$ is the proportion of the self-consumption electricity to total electricity production; $t_{\mathrm{VAT}}$ is added-value tax (VAT) rate; $\pi_{i}$ represents government tax subsidies.

The taxes costs for CSP projects mainly involve income tax and additional taxes; that is,

$$
\text { TAX }_{i}=\text { income tax }_{i}+\text { additional tax }_{i},
$$

where the income tax can be expressed as

$$
\begin{aligned}
& \text { income tax }_{i} \\
& =\left[\frac{\left(P \times E_{i}\right)(1-\alpha)}{\left(1+t_{\mathrm{VAT}}\right)}+\pi_{i}-(\mathrm{O} \& \mathrm{M}+I) C-R_{i}-\mathrm{DE}_{i}\right] \\
& \quad \times t_{\text {income }},
\end{aligned}
$$

where $\mathrm{DE}_{i}$ is the annual depreciation expense and $t_{\text {income }}$ represents the income tax rate.

VAT is not a cash outflow but directly determines the government tax subsidies and additional taxes. According to the notice of NEA on reducing the tax and fees burdens for the renewable energy companies, CSP in China could enjoy the taxes preference policy to refund $50 \%$ of VAT [27]. Thus we can obtain

$$
\begin{aligned}
\pi_{i} & =50 \% \times \mathrm{VAT}_{i} \\
\text { additional tax } & =\mathrm{VAT}_{i} \times t_{\text {additional }} .
\end{aligned}
$$

(1) Payback Period. The equation on SP is

$$
\sum_{i=1}^{\mathrm{SP}}(\mathrm{CI}-\mathrm{CO})_{i}=0 .
$$

The SP can be obtained by calculating the cumulative net cash flows, based on the cash flow statement of CSP project investment. SP is the time point where the cumulative net cash flows turn from negative value to positive value. Equation (5) can be expressed as

$$
\mathrm{SP}=T_{1}-1+\frac{\left|\sum_{i=1}^{T_{1}-1}(\mathrm{CI}-\mathrm{CO})_{i}\right|}{(\mathrm{CI}-\mathrm{CO})_{T_{1}}}
$$

where $T_{1}$ is the number of years when the cumulative net cash flows are positive or zero for the first time.

(2) Net Present Value. NPV is the dynamic index to evaluate the profit ability of CSP project during the calculation period. The formula of NPV is

$$
\mathrm{NPV}=\sum_{i=1}^{T}(\mathrm{CI}-\mathrm{CO})_{i}\left(1+r_{e}\right)^{-i+1},
$$

where $r_{e}$ is benchmark yield or discount rate.

NPV is the absolute index to evaluate the profit ability of CSP projects. When NPV $>0$, it indicates that CSP projects could get excess earnings on the basis of meeting the profitability that is required by the benchmark yield; that is, the investment of the CSP projects has strong economic feasibility. If NPV $=0$, it illustrates that the CSP projects are only able to meet the profitability required by the discount rate, which means that the investment for the CSP projects is basically feasible or to be improved, while NPV $<0$ indicates that the CSP projects cannot achieve the profitability of benchmark yield, and their investment is not feasible.

Besides, the magnitude of NPV depends not only on the profitability but also on the total investment or projects scale. If NPV > 0, the NPV is positively correlated with the total investment; that is, the bigger the total investment, the bigger the NPV. If NPV $<0$, the NPV is negatively correlated with the total investment. Therefore, in general, NPV cannot be used to compare the profitability between different CSP projects.

(3) Net Present Value Rate. NPVR is the ratio of the NPV of a project to the present value of its total investment. It reflects the unit of investment profitability. NPVR can be used as the auxiliary evaluation index of NPV and evaluate the profitability between different CSP projects. The formula of NPVR is as follows:

$$
\begin{aligned}
\mathrm{NPVR} & =\frac{\mathrm{NPV}}{\mathrm{II}_{p}} \\
\mathrm{II}_{p} & =\sum_{i=1}^{T_{0}} \mathrm{II}_{i}\left(1+r_{e}\right)^{-i},
\end{aligned}
$$

where $\mathrm{II}_{p}$ represents the present value of total investment.

(4) Internal Rate of Return. In the engineering economic analysis, IRR is the main dynamic evaluation index to investigate the profitability of projects. IRR reflects the profitability of the unrecovered funds occupied by the CSP projects, namely, 
TABLE 1: Design parameters of CSP demonstration plants.

\begin{tabular}{|c|c|c|c|c|c|c|}
\hline Number & Projects & $\begin{array}{c}\text { DNI } \\
\left(\mathrm{kWh} / \mathrm{m}^{2} / \mathrm{yr}\right)\end{array}$ & $\begin{array}{l}\text { Total investment } \\
\text { (million RMB) }\end{array}$ & $\begin{array}{l}\text { Annual power } \\
\text { generation } \\
(\mathrm{GWh} / \mathrm{yr})\end{array}$ & TES capacity & TES medium \\
\hline $\mathrm{ST}_{1}[32]$ & $\begin{array}{c}\text { Qinghai Delingha } 50 \text { MW MS ST-CSP } \\
\text { plant }\end{array}$ & 1,976 & 1,050 & 136 & $6 \mathrm{~h}$ & MS \\
\hline $\mathrm{ST}_{2}[33]$ & Dunhuang 100 MW MS ST-CSP plant & 2,000 & 3,040 & 483 & $11 \mathrm{~h}$ & MS \\
\hline $\mathrm{ST}_{3}[34]$ & $\begin{array}{c}\text { Qinghai Gonghe } 50 \text { MW MS ST-CSP } \\
\text { plant }\end{array}$ & 1,900 & 1,222 & 156.9 & $6 \mathrm{~h}$ & MS \\
\hline $\mathrm{ST}_{4}[35]$ & Xinjiang Hami 50 MW MS ST-CSP plant & 1,920 & 1,580 & 198.4 & $8 \mathrm{~h}$ & MS \\
\hline $\mathrm{ST}_{5}[32]$ & Delingha 135 MW DSG ST-CSP plant & 1,900 & - & - & $3.7 \mathrm{~h}$ & MS \\
\hline $\mathrm{ST}_{6}[36]$ & Gansu Jinta 100 MW MS ST-CSP plant & 1,900 & 2,500 & 323.2 & $8 \mathrm{~h}$ & MS \\
\hline $\mathrm{ST}_{7}[37]$ & Yumen 50 MW MS ST-CSP plant & 1,800 & 1,790 & 216 & $9 \mathrm{~h}$ & MS \\
\hline $\mathrm{ST}_{8}[38]$ & Yumen 100 MW MS ST-CSP plant & 1,800 & 3,000 & 388 & $10 \mathrm{~h}$ & MS \\
\hline $\mathrm{ST}_{9}[32]$ & Shangyi 50 MW DSG ST-CSP plant & 1,600 & - & - & $12 \mathrm{~h}$ & MS \\
\hline $\mathrm{PT}_{1}[39]$ & $\begin{array}{l}\text { Yumen East Town } 50 \text { MW TO PT-CSP } \\
\text { plant (Royal tech CSP Co., Ltd.) }\end{array}$ & 1,800 & $1,344.77$ & 169.3 & $9 \mathrm{~h}$ & MS \\
\hline $\mathrm{PT}_{2}[32]$ & Gansu Akesai 50 MW MS PT-CSP plant & $2,056.5$ & 1,986 & 256 & $15 \mathrm{~h}$ & MS \\
\hline $\mathrm{PT}_{3}[32]$ & $\begin{array}{c}\text { Yumen East Town } 50 \text { MW TO PT CSP } \\
\text { plant (Rayspower Energy Group Co., } \\
\text { Ltd.) }\end{array}$ & 1,800 & - & - & $9 \mathrm{~h}$ & MS \\
\hline $\mathrm{PT}_{4}[40]$ & $\begin{array}{c}\text { Urat Middle Banner } 100 \text { MW TO PT-CSP } \\
\text { plant }\end{array}$ & 2,025 & 2,800 & 350 & $10 \mathrm{~h}$ & MS \\
\hline $\mathrm{PT}_{5}[32]$ & Delingha 50 MW TO PT-CSP plant & 1,976 & $1,938.38$ & 225 & $9 \mathrm{~h}$ & MS \\
\hline $\mathrm{PT}_{6}[32]$ & Gansu Gulang 100 MW TO PT-CSP plant & 1,913 & - & - & $7 \mathrm{~h}$ & MS \\
\hline $\mathrm{PT}_{7}[41,42]$ & Zhangjiakou 64 MW MS PT-CSP plant & 1,700 & 1,800 & 300 & $16 \mathrm{~h}$ & MS \\
\hline $\mathrm{LF}_{1}[43]$ & $\begin{array}{c}\text { Dacheng Dunhuang } 50 \text { MW MS LF-CSP } \\
\text { plant }\end{array}$ & 2,000 & 1,680 & 201.5 & $13 \mathrm{~h}$ & MS \\
\hline $\mathrm{LF}_{2}[32]$ & Zhangbei 50 MW DSG LF-CSP plant & 1,750 & - & - & $14 \mathrm{~h}$ & ASSC \\
\hline $\mathrm{LF}_{3}[44,45]$ & $\begin{array}{c}\text { Huaqiang Zhaoyang Zhangjiakou } 50 \mathrm{MW} \\
\text { DSG LF-CSP plant }\end{array}$ & 1,750 & 1,800 & 250 & $14 \mathrm{~h}$ & ASSC \\
\hline $\mathrm{LF}_{4}[46]$ & $\begin{array}{c}\text { Urat Middle Banner } 50 \text { MW TO LF-CSP } \\
\text { plant }\end{array}$ & 2,025 & 1,476 & 195.88 & $8 \mathrm{~h}$ & MS \\
\hline
\end{tabular}

Note. MS: molten salt; TO: thermal oil; ASSC: all solid state concrete; DSG: direct steam generation.

the profitability of the projects themselves. The higher the IRR, the better the economy of projects. For CSP projects, IRR is the discount rate that makes the NPV zero and the mathematical expression is

$$
\mathrm{NPV}(\mathrm{IRR})=\sum_{i=1}^{T}(\mathrm{CI}-\mathrm{CO})_{i}(1+\mathrm{IRR})^{-i+1} .
$$

It indicates that the calculation of IRR determined by (9) has to be solved for the higher order equation. This process is very tedious and difficult. Therefore, in actual projects, the linear interpolation is usually used to calculate the approximate value of IRR, and the linear interpolation formula of IRR is as follows:

$$
\operatorname{IRR}=r_{1}+\frac{\operatorname{NPV}\left(r_{1}\right)}{\operatorname{NPV}\left(r_{1}\right)+\left|\operatorname{NPV}\left(r_{2}\right)\right|}\left(r_{2}-r_{1}\right),
$$

where $\operatorname{NPV}\left(r_{1}\right)>0, \operatorname{NPV}\left(r_{2}\right)<0, r_{2}>r_{1}$, and the value of $\left(r_{2}-r_{1}\right)$ should be not more than $2 \%$.

\section{Results and Discussions}

3.1. Data. Table 1 displays the basic information on the first twenty CSP demonstration projects of China, including nine ST-CSP projects, seven PT-CSP plants, and four LF-SCP projects.

According to Table 1, these demonstration projects are distributed in Gansu, Qinghai, Hebei, Inner Mongolia, and Xinjiang which are abundant in solar resources. The heat transfer fluids include molten salt, thermal oil, and water/ steam, with the molten salt and thermal oil primarily. The TES medium includes molten salt and all solid state concrete. Table 1 shows that the initial costs of CSP demonstration plants vary between RMB21.0/W and RMB39.7/W and the annual effective operation hours change from $2720 \mathrm{~h}$ to $5120 \mathrm{~h}$, due to the impacts of regions conditions, direct normal irradiation (DNI), CSP technologies, TES capacity, and so on (given the lack of design parameters for $\mathrm{ST}_{5}$, $\mathrm{ST}_{9}, \mathrm{PT}_{3}, \mathrm{PT}_{6}$, and $\mathrm{LF}_{2}$ projects, the analysis and discussion for the costs and benefits of CSP will not involve these five projects in the study). Simply from the CSP technologies 
perspectives, the average TES capacity of ST, PT and LR CSP systems are respectively $8 \mathrm{~h}, 10 \mathrm{~h}$ and $12 \mathrm{~h}$. Correspondingly, the average initial costs and annual effective operation hours are RMB28.6/W and $3750 \mathrm{~h}$ for ST-CSP systems, RMB31.4/W and $4140 \mathrm{~h}$ for PT-CSP systems, and RMB33.0/W and $4320 \mathrm{~h}$ for LF-CSP systems. Solely from the regions perspectives, the average TES capacity of CSP systems in Hebei, Gansu, Inner Mongolia, and Qinghai is $15 \mathrm{~h}, 10 \mathrm{~h}, 9 \mathrm{~h}$, and $7 \mathrm{~h}$, respectively. Accordingly, the average initial costs and annual effective operation hours of CSP systems are RMB31.6/W and $4825 \mathrm{~h}$ in Hebei, RMB30.7/W and 4074h in Gansu, RMB28.5/W and $3693 \mathrm{~h}$ in Inner Mongolia, RMB28.5/W and $3693 \mathrm{~h}$ in Qinghai. Thus it can be seen that the TES capacity has crucial influence on the initial costs and annual electricity production of CSP. Besides, from projects perspectives, the TES capacity has also an important impact on the CSP systems. In general, the larger the TES capacity, the higher the initial costs and annual electricity generation. Taking the $\mathrm{ST}_{1}$ project, for example, the TES capacity is the smallest but both the initial costs and annual effective operation hours are also lower than those of other CSP projects. For the $\mathrm{PT}_{2}$ project, its TES is higher than that of other CSP projects apart from the $\mathrm{PT}_{7}$ project and both its initial costs and annual effective operation hours are the highest.

According to the notice on organizing the construction of CSP demonstration projects, the National Energy Administration (NEA) required that the equity capital ratio cannot be less than 20\%; the loan rate could be a reference to the actual commercial loan interest rate; the construction period and operation period were set as 2 years and 25 years, respectively [28]. In 2016, the long-term loan interest rate of China was $4.9 \%$. The initial costs are divided into land cost and construction costs and the proportions of both costs are $4 \%$ and $96 \%$, respectively [26]. Due to no fuel consumption, the O\&M costs are very low and usually account for about $2 \%$ of construction costs [29]. Besides, it is necessary for CSP projects to adopt an insurance measure to decrease the risks caused by high initial investment and immature technology; the ratio between insurance expense and construction costs is considered to be $0.5 \%[14,30]$.

The proportion of the self-consumption electricity in total electricity production was usually set at $10 \%$; both repayment period and depreciation period were 15 years [31]. In China, CSP demonstration plants could enjoy the income tax concession with full exemption in the first three years; then it was half exemption for the income tax in the second three years, and the income tax rate is reduced from $25 \%$ to $15 \%$. The rates of value-added tax (VAT) and additional taxes are $17 \%$ and $8 \%$, respectively [22]. Therefore, this paper could obtain the values of parameters and data related to the CSP systems of China as described in Table 2.

3.2. Cost-Benefit Evaluation. The cost-benefit is to examine the economic efficiency of CSP projects and it has an important effect on the investment decisions and policymaking of CSP industry. At present, the CSP in China has entered the stage of commercial demonstration development. The first CSP demonstration plants of China were approved formally by the National Energy Administration (NEA). With
TABLE 2: Parameters values and data related to the CSP systems of China.

\begin{tabular}{lc}
\hline Basic parameter & Values \\
\hline Benchmark FIT $(P)[2]$ & RMB1.15/kWh \\
Initial investment $(\mathrm{II})$ & See Table 1 \\
O\&M costs ratio $(\mathrm{OM})[29]$ & $2 \%$ \\
Operation period $\left(T-T_{0}\right)[29]$ & 25 years \\
Repayment period [31] & 15 years \\
Long-term loan rate $(r)$ & $4.9 \%$ \\
VAT rate $\left(t_{\mathrm{VAT}}\right)[22]$ & $17 \%$ \\
Additional taxes ratio $\left(t_{\text {additional }}\right)[22]$ & $8 \%$ \\
Proportion of self-consumption electricity $(\alpha)$ & $10 \%$ \\
[31] & See Table 1 \\
Annual generation electricity $\left(E_{i}\right)$ & $96 \%$ \\
Construction costs ratio $(C)[26]$ & $0.5 \%$ \\
Insurance expenses ratio $(I)[14,30]$ & 2 years \\
Construction period $\left(T_{0}\right)[28]$ & 15 years \\
Depreciation period [22] & $10 \%$ \\
Discount rate $\left(r_{e}\right)[31]$ & $15 \%$ \\
Income tax rate $\left(t_{\text {income }}\right)[22]$ & $80 \%$ \\
Loan ratio [28] &
\end{tabular}

the start-up of CSP demonstration projects, more and more renewable energy investors began to pay attention to the CSP development of China. The costs and benefits of CSP demonstration plants have a direct impact on the investors' willingness to invest in the CSP industry and the results can provide scientific basis for the policy makers to improve the industrial policies.

The first CSP demonstration projects of China involved the ST, PT, and LF-CSP technologies, which are encouraged by NEA [28]. Therefore, in order to fully analyze the costbenefit of CSP in China, this study selected SP, NPV, NPVR, and IRR as measured indicators to calculate and discuss the cost-benefit of ST, PT, and LF-CSP technologies, respectively.

3.2.1. Solar Tower CSP. Table 3 shows the cost-benefit for the ST-CSP demonstration plants of China. The SP of ST-CSP projects vary from 7.3 years to 16.4 years. Apart from $\mathrm{ST}_{2}$ project, the SP of other ST-CSP plants are all more than 13 years. Besides, the average SP of ST-CSP technology is about 12.0 years. It means that the investors of ST-CSP plants have to take long time to recover the initial capital due to the huge upfront investment. The NPV of ST-CSP systems are between RMB-52.0 million and RMB676.8 million. Further analysis shows that the NPV of $\mathrm{ST}_{7}$ project is less than zero and the NPV of the remaining ST plants are all more than zero. It means that only the investment for $\mathrm{ST}_{7}$ project cannot meet the profitability required by the benchmark yield of $10 \%$ and other ST-CSP plants are all able to get excess earnings on the basis of realizing the benchmark profitability.

The NPVR of ST-CSP plants are between -0.15 and -1.11 . The average NPVR of ST-CSP technology is approximately 0.30 ; the IRR of ST-CSP systems are between $8.89 \%$ and 
TABLE 3: Cost-benefit for the ST-CSP technology of China.

\begin{tabular}{|c|c|c|c|c|c|c|c|c|}
\hline & $\mathrm{ST}_{1}$ & $\mathrm{ST}_{2}$ & $\mathrm{ST}_{3}$ & $\mathrm{ST}_{4}$ & $\mathrm{ST}_{6}$ & $\mathrm{ST}_{7}$ & $\mathrm{ST}_{8}$ & Mean \\
\hline $\mathrm{DNI}\left(\mathrm{kWh} / \mathrm{m}^{2} / \mathrm{yr}\right)$ & 1,976 & 2,000 & 1,900 & 1,900 & 1,900 & 1,800 & 1,800 & - \\
\hline Initial costs $(\mathrm{RMB} / \mathrm{W})$ & 21 & 30.4 & 24.44 & 31.6 & 25 & 35.8 & 30 & - \\
\hline TES capacity (h) & 6 & 11 & 6 & 8 & 8 & 9 & 10 & - \\
\hline SP (years) & 13.3 & 7.3 & 13.7 & 14.6 & 13.4 & 16.4 & 13.4 & 12.0 \\
\hline NPV (Million RMB) & 30.7 & 676.8 & 26.7 & 5.0 & 69.1 & -52.0 & 84.0 & - \\
\hline NPVR & 0.15 & 1.11 & 0.11 & 0.02 & 0.14 & -0.15 & 0.14 & 0.30 \\
\hline IRR & $11.14 \%$ & $19.22 \%$ & $10.85 \%$ & $10.12 \%$ & $11.08 \%$ & $8.89 \%$ & $11.09 \%$ & $12.33 \%$ \\
\hline
\end{tabular}

TABLE 4: Cost-benefit for the PT-CSP technology of China.

\begin{tabular}{lcccccc}
\hline & $\mathrm{PT}_{1}$ & $\mathrm{PT}_{2}$ & $\mathrm{PT}_{4}$ & $\mathrm{PT}_{5}$ & $\mathrm{PT}_{7}$ & $\mathrm{Mean}$ \\
\hline DNI $\left(\mathrm{kWh} / \mathrm{m}^{2} / \mathrm{yr}\right)$ & 1,800 & $2,056.5$ & 2,025 & 1,976 & 1,700 & - \\
Initial costs $(\mathrm{RMB} / \mathrm{W})$ & 26.90 & 39.72 & 28.00 & 38.77 & - \\
TES capacity (h) & 9 & 15 & 10 & 9 & 16 & - \\
SP (years) & 14.5 & 13.5 & 14.8 & 17.6 & 6.5 & 12.6 \\
NPV (Million RMB) & 7.2 & 49.9 & -1.6 & -115.0 & - & 493.0 \\
NPVR & 0.03 & 0.13 & 0.00 & -0.30 & 1.37 & 0.22 \\
IRR & $10.21 \%$ & $10.98 \%$ & $9.98 \%$ & $7.75 \%$ & $21.50 \%$ & $11.72 \%$ \\
\hline
\end{tabular}

$19.22 \%$, and the average IRR of investment for ST-CSP technology is about $12.33 \%$. Thus it can be seen that the costbenefit of ST-CSP technology is better since its average NPVR is more than zero, and its average IRR is higher than the benchmark yield of $10 \%$. Further analysis shows that the costbenefit of $\mathrm{ST}_{2}$ plant, with NPVR of 1.11 and IRR of $19.22 \%$, is better than that of other ST-CSP plants due to higher DNI and larger TES capacity. The $\mathrm{ST}_{1}$ plant is second, with NPVR of 0.15 and IRR of $11.14 \%$, because of its higher DNI and lower initial costs. The $\mathrm{ST}_{8}$ project is next with NPVR of 0.14 and IRR of $11.09 \%$ due to its larger TES capacity, followed by the $\mathrm{ST}_{6}$ project with NPVR of 0.14 and IRR of $11.08 \%$ due to lower initial costs. The cost-benefit of $\mathrm{ST}_{7}$ project, with NPVR of -0.15 and IRR of $8.89 \%$, is the worst of all the ST-CSP projects because of its lower DNI and higher initial costs; followed by $\mathrm{ST}_{4}$ project with NPVR of 0.02 and IRR of $10.12 \%$ because of its higher initial costs; and finally $\mathrm{ST}_{3}$ project with NPVR of 0.11 and IRR of $10.85 \%$, because of smaller TES capacity.

3.2.2. Parabolic Trough CSP. Table 4 shows the cost-benefit for the PT-CSP demonstration plants of China. The SP of PTCSP projects are between 6.5 years and 17.6 years and the SP of other PT-CSP plants are all more than 13.5 years except for $\mathrm{PT}_{7}$ project. In addition, the average SP of investment for PT-CSP technology is approximately 12.6 years and longer than that of PT-CSP technology. Thus it can be seen that the investors of PT-CSP plants need to take a longer time to recover the initial investment. The NPV of PT-CSP plants vary from RMB-115.0 million to RMB493.0 million; in which, the NPV of both $\mathrm{PT}_{4}$ and $\mathrm{PT}_{5}$ projects are less than zero, and the remaining PT-CSP plants are more than zero. It illustrates that the investment for both $\mathrm{PT}_{4}$ and $\mathrm{PT}_{5}$ projects cannot meet the profitability required by the benchmark yield of $10 \%$, but $\mathrm{PT}_{1}, \mathrm{PT}_{2}$, and $\mathrm{PT}_{7}$ projects could obtain excessive profits based on achieving the benchmark profitability.

The NPVR of PT-CSP projects vary between -0.30 and 1.37, and the average NPVR for PT-CSP technology is approximately 0.22 . The IRR of investment for PT-CSP projects are in the range of $7.75 \%-21.50 \%$ and the average IRR of investment for PT-CSP technology is approximately $11.72 \%$. It means that the cost-benefit for some PT-CSP plants is worse, but overall it is good for LF-CSP technology because its average NPVR is more than zero and its average IRR is higher than the benchmark yield of $10 \%$. Besides, the costbenefit of ST-CSP technology is better than that of PT-CSP technology since both the average NPVR and IRR of the STCSP are more than that of PT-CSP. The cost-benefit of $\mathrm{PT}_{7}$ project, with NPVR of 1.37 and IRR of $21.50 \%$, is better than that of other PT-CSP plants, because of its larger TES capacity. The $\mathrm{PT}_{2}$ project is the second project, with NPVR of 0.13 and IRR of $10.98 \%$, due to the higher DNI and larger TES capacity; followed by $\mathrm{PT}_{1}$ project with NPVR of 0.03 and IRR of $10.21 \%$ because of the lower initial costs. In addition, the cost-benefit of $\mathrm{PT}_{5}$ project, with NPVR of -0.30 and IRR of $7.75 \%$, is the last of the PT-CSP projects because of its higher initial costs and smaller TES capacity.

3.2.3. Linear Fresnel CSP. Table 5 shows the cost-benefit for the LF-CSP demonstration plants of China. The SP of LFCSP projects vary between 10.7 years and 16.7 years and the average SP for LF technology is about 13.0 years. The payback period of LF-CSP technology is longer than that of ST and PTCSP technologies. The NPV of LF-CSP systems are between RMB-56.9 million and RMB163.7 million; the NPV for $\mathrm{LF}_{1}$ project is less than zero and for both $\mathrm{LF}_{3}$ and $\mathrm{LF}_{4}$ plants it is more than zero. It indicates that the investment for $\mathrm{LF}_{1}$ plant cannot achieve the profitability required by the benchmark 
TABLE 5: Cost-benefit for the LF CSP of China.

\begin{tabular}{lcccc}
\hline & $\mathrm{LF}_{1}$ & $\mathrm{LF}_{3}$ & $\mathrm{LF}_{4}$ & $\mathrm{Mean}$ \\
\hline DNI $\left(\mathrm{kWh} / \mathrm{m}^{2} / \mathrm{yr}\right)$ & 2,000 & 1,750 & 2,025 & - \\
Initial costs $(\mathrm{RMB} / \mathrm{W})$ & 33.60 & 36.00 & 29.52 & 8 \\
TES capacity $(\mathrm{h})$ & 13 & 14 & $\mathrm{M}-\mathrm{S}$ & - \\
TES medium & $\mathrm{M}-\mathrm{S}$ & $\mathrm{A}-\mathrm{S}-\mathrm{S}-\mathrm{C}$ & 1.3 & - \\
SP (years) & 16.7 & 10.7 & 74.1 & 13.0 \\
NPV (Million RMB) & -56.9 & 0.45 & 0.25 & - \\
NPVR & -0.17 & $13.61 \%$ & $11.97 \%$ & 0.18 \\
IRR & $8.70 \%$ & & $11.43 \%$ \\
\hline
\end{tabular}

yield of $10 \%$. But the investment of $\mathrm{LF}_{3}$ and $\mathrm{LF}_{4}$ plants can obtain excess earnings on the basis of meeting the benchmark profitability.

The NPVR of LF-CSP projects vary from -0.17 to -0.45 and the average NPVR for LF-CSP technology is approximately 0.18 . The IRR of investment for LF-CSP systems vary from $8.70 \%$ to $13.61 \%$, and the average IRR of investment for LF-CSP technology is about $11.43 \%$. Thus it can be seen that the cost-benefit of LF-CSP technology overall is good but worse than that of ST and PT-CSP technologies. Further analysis shows that the cost-benefit of $\mathrm{LF}_{3}$ plant, with NPVR of 0.45 and IRR of $13.61 \%$, is better than that of other two LF-CSP projects, due to the larger TES capacity and the application of advanced TES medium (i.e., all solid state concrete), followed by $\mathrm{LF}_{4}$ plant with NPVR of 0.25 and IRR of $11.97 \%$, because of the higher DNI and lower initial costs. The cost-benefit of $\mathrm{LF}_{1}$ plant, with NPVR of -0.17 and IRR of $8.70 \%$, is the lowest among all the LF-CSP plants, due to the higher initial costs.

3.3. Sensitivity Analysis. The cost-benefit analysis for CSP requires comprehensively considering the impacts of sensitivity factors, mainly involving annual electricity production, initial investment, O\&M expenses, and interest rate. The study selected IRR as the evaluation index to discuss the impacts of these sensitivity factors on the cost-benefit of ST, PT, and LF-CSP technologies respectively; and the variation range is set as $\pm 20 \%$.

3.3.1. Annual Electricity Production. Figure 1 shows the effects of annual electricity production on the IRR of three different CSP technologies. An increase by $20 \%$ of the annual electricity production will cause the IRR to increase from $12.33 \%$ to $19.80 \%$ for ST-CSP technology, from $11.72 \%$ to $18.99 \%$ for PT-CSP technology, and from $11.43 \%$ to $18.60 \%$ for LF-CSP technology. However, if the annual electricity production is decreased by $20 \%$, the IRR of ST, PT, and LF-CSP technologies will decrease to $5.38 \%, 4.89 \%$, and $4.65 \%$, respectively. Thus, it can be seen that increasing the annual electricity production could effectively improve the cost-benefit of CSP systems, but reducing it will have a very negative effect on the cost-benefit of CSP systems. Therefore, increasing the annual electricity production is crucial for the improvement of the cost-benefit of CSP systems.

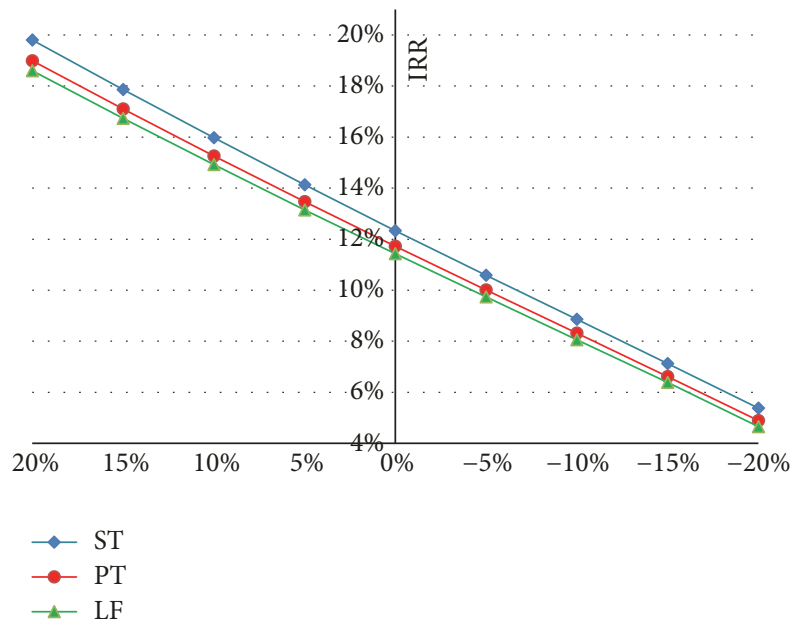

FIGURE 1: The sensitivity analysis results of the IRR of CSP to the annual electricity production.

The annual electricity production determines the incomes directly and has an important effect on the costbenefit. Annual electric generation capacity of CSP systems is determined by the thermal conversion efficiency, DNI, TES capacity, and so on. For the three CSP technologies involved in the first CSP demonstration projects of China, the thermodynamic efficiency of ST-CSP technology is higher than that of other two CSP technologies, in view of the higher temperatures that the heat transfer fluids in the ST systems could achieve; so the ST systems could significantly increase the thermal conversion efficiency of ST-CSP plants in relatively lower costs. PT-CSP technology is second. Although it has been widely adopted among the existing CSP plants, its potential for development may be limited by the low thermodynamic efficiency. LF-CSP technology is the simplified technique of PT-CSP systems, and its thermal conversion efficiency is less than that of other two CSP technologies; meaning that the LF systems need a relatively higher cost to increase the thermodynamic efficiency of LFCSP systems. Accordingly, the average IRR of investment for ST-CSP technology of $12.33 \%$ is higher than that of PT-CSP technology of $11.72 \%$ and LF-CSP technology of $11.43 \%$. DNI and TES technology have also important effects on the annual generation capacity of CSP. Excluding the impacts of other factors, a higher DNI implies a better electricity production 


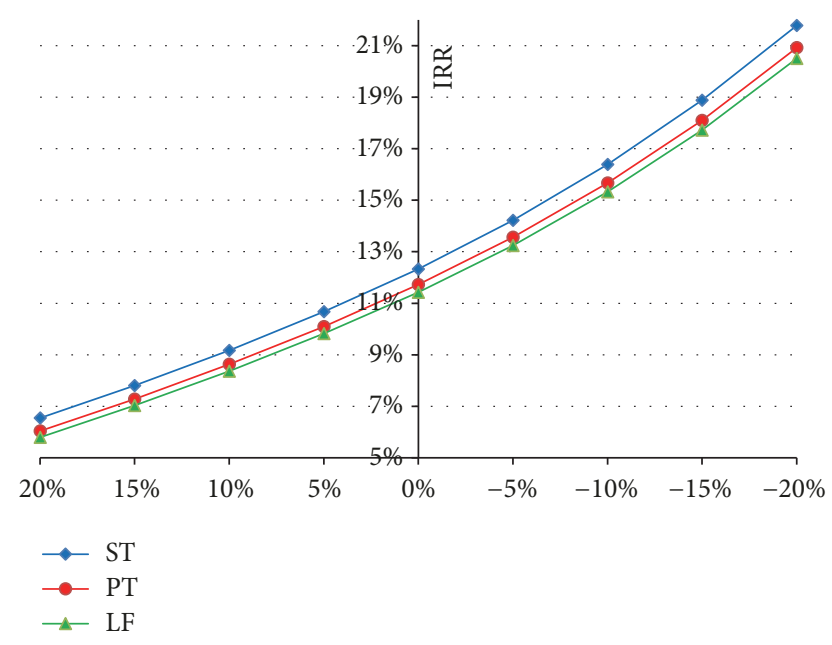

FIGURE 2: The sensitivity analysis results of the IRR of CSP to the initial costs.

of CSP systems in a year. So it is necessary for CSP plants to select the sites with higher DNI, in order to increase the annual electricity production and improve the cost-benefit of CSP. Besides, the installation of TES systems adds to the initial investment but could improve the capacity factor of CSP systems and increase the annual electricity production.

3.3.2. Initial Costs. Figure 2 displays the effects of initial costs on the IRR of three different CSP technologies. When the initial costs are reduced by $20 \%$, the IRR will increase from $12.33 \%$ to $21.78 \%$ for ST-CSP technology, from $11.72 \%$ to $20.92 \%$ for PT-CSP technology, and from $11.43 \%$ to $20.50 \%$ for LF-CSP technology. If increased by $20 \%$, the IRR of ST, PT, and LF-CSP technologies will decline to 6.54\%, 6.04\%, and $5.79 \%$, respectively. Thus, it can be seen that the effects of initial costs reduction on the IRR of CSP are greater than that of initial costs increase. Reducing the initial costs can effectively improve the cost-benefit of CSP, while its increase has negative effect on the cost-benefit of CSP. Therefore, reducing the initial costs is crucial for improving the costbenefit of CSP systems.

High initial investment has been the main obstacle for the development of CSP. As seen in Table 1, the initial costs of CSP vary between RMB21/W and RMB39.72/W and they are higher than that of traditional energy generation technologies. With growth of cumulative installed capacity and technology progress, the initial costs of CSP will be reduced greatly in the future [47]. On the one hand, with the expansion of projects scale and CSP market, larger CSP plants will be designed and constructed. The mass production of the equipment and materials and the optimization of CSP systems could dramatically reduce the initial costs. On the other hand, the experience gained by professional technical personnel, engineers, and contractors through the accumulation of the construction of CSP projects will improve the design and construction scheme of CSP plants to reduce the initial costs. This experience is usually characterized by learning curves. Based on the learning curves theory, the

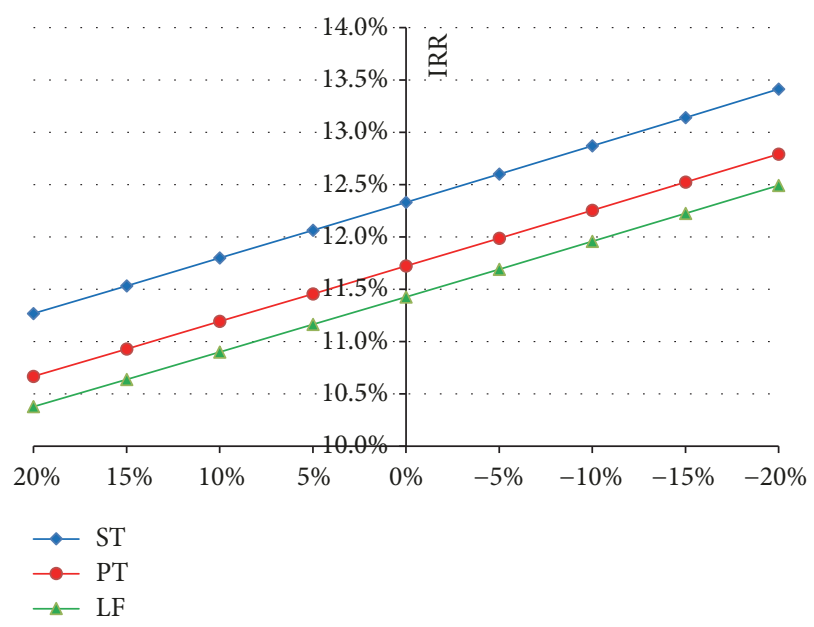

FIGURE 3: The sensitivity analysis results of the IRR of CSP to the operation and maintenance costs.

decrease in the initial costs is proportional to the learning rate with the growth of total installed capacity. More specifically, if the learning rate of CSP industry is $10 \%$, the initial costs could be reduced by about $10 \%$ when the total installed capacity double.

3.3.3. Operation and Maintenance Costs. Figure 3 shows the impacts of O\&M costs on the IRR of three different CSP technologies. If the O\&M costs are increased by $20 \%$, the IRR of ST, PT, and LF-CSP technologies will decrease from $12.33 \%$, $11.72 \%$, and $11.43 \%$ to $11.27 \%, 10.67 \%$, and $10.38 \%$, respectively. When decreased by $20 \%$, the IRR will increase to $13.41 \%$ for ST-CSP technology, $12.79 \%$ for PT-CSP technology, and $12.49 \%$ for LF-CSP technology. Different from initial investment, the O\&M costs of CSP systems are relatively lower because of no fuel consumption. Accordingly, the impacts of O\&M costs on the IRR of CSP systems are relatively small. The IRR of CSP systems only increase by about $1.07 \%$ when the O\&M costs are reduced by $20 \%$.

With the construction and operation of CSP demonstration plants, the O\&M costs of CSP systems are expected to be reduced remarkably in the future. Therefore, the improvement of cost-benefit, which is caused by the reduction of O\&M costs, should not be ignored.

3.3.4. Interest Rate. Figure 4 shows the impacts of interest rate on the IRR of three different CSP technologies. When the interest rate is increased by $20 \%$, the IRR of ST, PT, and LF-CSP technologies will decrease from $12.33 \%, 11.72 \%$, and $11.43 \%$ to $11.03 \%, 10.46 \%$, and $10.18 \%$, respectively. If reduced by $20 \%$, the IRR will increase to $13.76 \%$ for ST-CSP technology, $13.11 \%$ for PT-CSP technology, and $12.80 \%$ for LFCSP technology, respectively. Although the effects of interest rate on the IRR of CSP systems are relatively low, it cannot be ignored.

CSP is a capital intensive industry. The investment and financing are crucial to the start-up of CSP projects due to high initial costs. The long-term commercial loan has been the main sources for the funding of CSP projects in China 


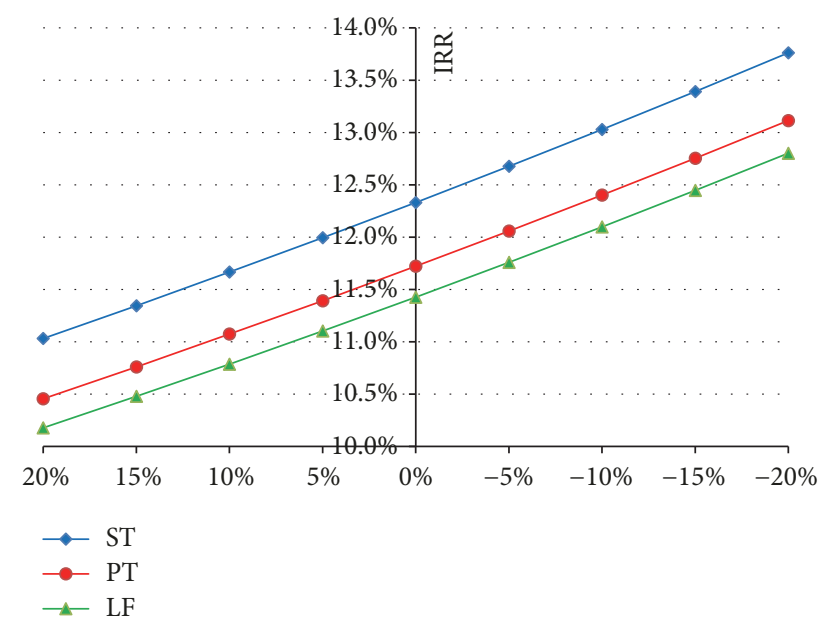

FIGURE 4: The sensitivity analysis results of the IRR of CSP to the interest rate.

and the loans ratio in the total investment could achieve $80 \%$. Therefore, the loan interest is also an important expenditure for the construction and operation of CSP plants. The interest rate determines the capitals cost directly and affects the equity capital benefit. The lower interest rate could decrease the loans interest and increase the IRR of CSP plants. Therefore, preferential loans play an important role in improving the cost-benefit of CSP technologies. In China, the low-interest loans can be obtained from policy banks such as China investment bank and Asian investment bank.

\section{Conclusions}

In 2016, with the implementation of the first batch CSP demonstration projects, China made ambitious development goals for CSP industry. The cost-benefit has an important impact on the investment discussions and policy-making; the cost-benefit analysis for CSP demonstration plants is therefore of great significance for the development of CSP industry in China. Based on the related data and design parameters of the first CSP demonstration projects, this study adopted financial indicators, including SP, NPV, NPVR, and IRR, to calculate and discuss the cost-benefit of different CSP technologies in China. The results showed the following.

Firstly, Analysis from Projects Perspective. The investment payback periods of most of CSP demonstration projects are more than 13 years, meaning that the CSP systems usually take a longer time to recover the initial investment, because of the huge upfront input. However, with the formulation and implementation of the benchmark FIT of CSP industry, the CSP demonstration projects could obtain good expected incomes in the operation period; so most of CSP projects are able to gain excess returns on the basis of realizing the benchmark profitability, which is required by the discounted rate of $10 \%$. That is, under the current technical level, policy system, and resource endowment of China, vast majority of CSP projects have a strong economic feasibility. Besides, the cost-benefit among CSP demonstration projects has large differences, due to the combined influence of region conditions, CSP technologies, DNI, initial costs, TES capacity, and so on. However, generally speaking, the larger TES capacity usually could bring a good cost-benefit just from the CSP projects perspectives.

Secondly, Calculation from the Perspective of Technologies. The average SP of ST, PT, and LF-CSP technologies are about 12 years, 12.6 years, and 13.0 years, respectively. Their average NVPR are, respectively, $0.30,0.22$, and 0.18 . Their average IRR of investment are $12.33 \%, 11.72 \%$, and $11.43 \%$, respectively. This indicates that the cost-benefit of ST-CSP technology is better than that of other two CSP technologies, because of the higher thermal conversion efficiency, closely followed by the PT-CSP technologies, which has been widely adopted among the existing CSP plants. The cost-benefit of LF-CSP technology is relatively worse, due to the lower thermodynamic efficiency. Thus it can be seen that the impacts of the types of technology on the cost-benefits of CSP are more important than those of TES capacity.

Thirdly, Discussions from the Perspective of Influencing Factors. The annual electricity production and initial costs have significant impacts on the cost-benefit of CSP systems. For each increase of $5 \%$ of annual electricity production, the IRR can be increased by about $1.87 \%$ for ST, $1.82 \%$ for PT, and $1.79 \%$ for LF-CSP technologies. Conversely, their IRR will be decreased by approximately $1.74 \%, 1.72 \%$, and $1.70 \%$, respectively. For each decrease of $5 \%$ of initial costs, the IRR can be increased by approximately $2.36 \%$ for ST, $2.30 \%$ for PT, and 2.27\% for LF-CSP technologies. Conversely, their IRR will be reduced by about $1.45 \%, 1.42 \%$, and $1.41 \%$, respectively. Besides, the effects of O\&M costs and loan interest rate on the cost-benefit of CSP systems are relatively less than the effects of the annual electricity production and initial costs, but cannot be ignored, especially the loan interest rate.

\section{Conflicts of Interest}

The authors declare that they have no conflicts of interest.

\section{Acknowledgments}

This paper is supported by National Social Science Foundation (Grant no. 16BJY055).

\section{References}

[1] Sino-Danish renewable energy development project administration office. The China Renewable Energy Development Roadmap of 2050 [Internet], C2014, National renewable energy center, 2014, http://www.docin.com/p-1151220292.html.

[2] National Development and Reform Commission (NDRC), NDRC issued "Notice on the benchmark feed-in tariff price policy of CSP" [Internet], C2016, NDRC, http://www.gov.cn/ xinwen/2016-09/01/content_5104496.htm.

[3] I. Purohit, P. Purohit, and S. Shekhar, "Evaluating the potential of concentrating solar power generation in Northwestern India," Energy Policy, vol. 62, pp. 157-175, 2013. 
[4] H. L. Zhang, J. Baeyens, J. Degrève, and G. Cacères, "Concentrated solar power plants: review and design methodology," Renewable \& Sustainable Energy Reviews, vol. 22, pp. 466-481, 2013.

[5] N. Caldés, M. Varela, M. Santamaría, and R. Sáez, "Economic impact of solar thermal electricity deployment in Spain," Energy Policy, vol. 37, no. 5, pp. 1628-1636, 2009.

[6] International Energy Agency (IEA), World energy outlook 2013: renewable energy outlook [dissertation], Paris, France, 2013, OGCDIIGA.

[7] F. Dinter and D. M. Gonzalez, "Operability, reliability and economic benefits of CSP with thermal energy storage: First year of operation of ANDASOL 3," in Proceedings of the International Conference on Solar Power and Chemical Energy Systems, SolarPACES 2013, pp. 2472-2481, USA, September 2013.

[8] R. Shinnar and F. Citro, "A road map to U.S. decarbonization," Science, vol. 313, no. 5791, pp. 1243-1244, 2006.

[9] Y. Tian and C. Y. Zhao, "A review of solar collectors and thermal energy storage in solar thermal applications," Applied Energy, vol. 104, pp. 538-553, 2013.

[10] R. Sioshansi and P. Denholm, "The value of concentrating solar power and thermal energy storage," IEEE Transactions on Sustainable Energy, vol. 1, no. 3, pp. 173-183, 2010.

[11] S. H. Madaeni, R. Sioshansi, and P. Denholm, "How thermal energy storage enhances the economic viability of concentrating solar power," Proceedings of the IEEE, vol. 100, no. 2, pp. 335347, 2012.

[12] International Renewable Energy Agency (IRENA), Renewable power generation costs in 2014 [dissertation], IRENA, 2015.

[13] Renewable Energy Policy Network for the 21st Century (REN $21)$, The first decade: ten years of renewable energy progress: 2004-2014 [dissertation], REN 21, 2015.

[14] C. Parrado, A. Marzo, E. Fuentealba, and A. G. Fernández, "2050 LCOE improvement using new molten salts for thermal energy storage in CSP plants," Renewable \& Sustainable Energy Reviews, vol. 57, pp. 505-514, 2016.

[15] C. Parrado, A. Girard, F. Simon, and E. Fuentealba, "2050 LCOE (Levelized Cost of Energy) projection for a hybrid PV (photovoltaic)-CSP (concentrated solar power) plant in the Atacama Desert, Chile," Energy, vol. 94, pp. 422-430, 2016.

[16] A. R. Starke, J. M. Cardemil, R. A. Escobar, and S. Colle, "Assessing the performance of hybrid CSP + PV plants in northern Chile," Solar Energy, vol. 138, pp. 88-97, 2016.

[17] X. Ju, C. Xu, Y. Hu, X. Han, G. Wei, and X. Du, "A review on the development of photovoltaic/concentrated solar power (PVCSP) hybrid systems," Solar Energy Materials \& Solar Cells, vol. 161, pp. 305-327, 2017.

[18] S. Izquierdo, C. Montañs, C. Dopazo, and N. Fueyo, "Analysis of CSP plants for the definition of energy policies: The influence on electricity cost of solar multiples, capacity factors and energy storage," Energy Policy, vol. 38, no. 10, pp. 6215-6221, 2010.

[19] J. Hernández-Moro and J. M. Martínez-Duart, "CSP electricity cost evolution and grid parities based on the IEA roadmaps," Energy Policy, vol. 41, pp. 184-192, 2012.

[20] F. Cao, Q. Liu, T. Yang, T. Zhu, J. Bai, and L. Zhao, "Full-year simulation of solar chimney power plants in Northwest China," Journal of Renewable Energy, vol. 119, pp. 421-428, 2018.

[21] X. Zhao, Y. Zeng, and D. Zhao, "Distributed solar photovoltaics in China: Policies and economic performance," Energy, vol. 88, pp. 572-583, 2015.
[22] J. Yuan, S. Sun, W. Zhang, and M. Xiong, "The economy of distributed PV in China," Energy, vol. 78, pp. 939-949, 2014.

[23] W. Li, P. Wei, and X. Zhou, "A cost-benefit analysis of power generation from commercial reinforced concrete solar chimney power plant," Energy Conversion and Management, vol. 79, pp. 104-113, 2014.

[24] P. Guo, Y. Zhai, X. Xu, and J. Li, "Assessment of levelized cost of electricity for a 10-MW solar chimney power plant in Yinchuan China," Energy Conversion and Management, vol. 152, pp. 176185, 2017.

[25] Z. Zhu, D. Zhang, P. Mischke, and X. Zhang, "Electricity generation costs of concentrated solar power technologies in China based on operational plants," Energy, vol. 89, pp. 65-74, 2015.

[26] Z.-Y. Zhao, Y.-L. Chen, and J. D. Thomson, "Levelized cost of energy modeling for concentrated solar power projects: A China study," Energy, vol. 120, pp. 117-127, 2017.

[27] CSPPLAZA, Notice of NEA on reducing the tax and fees burdens of the companies of renewable energy field [Internet], c2017, CSPPLAZA, http://www.cspplaza.com/article-10455-1 .html.

[28] NEA, Notice of NEA on organizing the construction of CSP demonstration projects [Internet], NEA, c2017, http://zfxxgk .nea.gov.cn/auto87/201509/t20150930_1968.htm.

[29] J. Hernández-Moro and J. M. Martínez-Duart, "Analytical model for solar PV and CSP electricity costs: Present LCOE values and their future evolution," Renewable \& Sustainable Energy Reviews, vol. 20, pp. 119-132, 2013.

[30] P. Viebahn, Y. Lechon, and F. Trieb, "The potential role of concentrated solar power (CSP) in Africa and Europe-A dynamic assessment of technology development, cost development and life cycle inventories until 2050," Energy Policy, vol. 39, no. 8, pp. 4420-4430, 2011.

[31] Inner Mongolia Electric Power Survey and Design Institute, Pre-feasibility study report on the Inner Mongolia 50MW trough solar thermal power demonstration project [dissertation], 2008.

[32] CSPPLAZA, The brief introduction for the first batch twenty CSP demonstration projects [Internet], CSPPLAZA, c2016, http://guangfu.bjx.com.cn/news/20160926/775762.shtml.

[33] Shouhang energy saving co. LTD, The reply of Shouhang and INDUSTRIAL SECURITIES on "Feedback on the non-public offering of shares application documents of Beijing Shouhang Ihw Energy Saving Technology Co., Ltd" [Internet], Shouhang energy saving co. LTD, c2016, http://q.stock.sohu.com/ cn,gg,002665,2279028837.shtml.

[34] CSPPLAZA, Foundation laying for Gonghe 50MW molten salt ST-CSP project of Northwest Institute of survey and design [Internet], CSPPLAZA, c2017, http://www.cspplaza.com/article-9937-1.html.

[35] CSPPLAZA, Northwest Electric Power Design Institute won the EPC of Hami 50MW ST-CSP project of CHINA POWER ENGINEERING [Internet], CSPPLAZA, http://www.cspplaza .com/article-9367-1.html.

[36] Jinta100MW molten salt ST-CSP project of China Three Gorges New Energy Co., Ltd [Internet], c2017, http://www.bidnews.cn/ xiangmu/zhaobiao-67992.html.

[37] CSPPLAZA, Yumen Xinneng 50MW molten salt ST-CSP project obtained the construction permit [Internet], CSPPLAZA, c2017, http://www.cspplaza.com/article-9536-1.html.

[38] China state Department of Environmental Protection, Environmental impact assessment report publicity: Environmental impact assessment report on Yumen 100MW molten salt 
ST-CSP project of Guohua [Internet], CSPPLAZA, c2017, http://www.doc88.com/p-5496378980290.html.

[39] China state Department of Environmental Protection, Environmental impact assessment report publicity: Environmental impact assessment report on Yumen East Town 50MW thermal oil PT-CSP project [Internet], China state Department of Environmental Protection, c2017, http://www.docin.com/ p-1871037172.html.

[40] CSPPLAZA, WuLate Middle Banner 100MW thermal oil PTCSP project of China National Nuclear Longtium was started officially [Internet], CSPPLAZA, c2017, http://www.cspplaza .com/article-9458-1.html.

[41] CSPPLAZA, Foundation laying for Zhangjiakou 64MW molten salt PT-CSP plant of Zhongyang [Internet], CSPPLAZA, c2014, http://www.cspplaza.com/article-3735-1.html.

[42] CSPPLAZA, Zhangjiakou 64MW molten salt PT-CSP plant of Zhongyang would be centralized bidding next month, financing was almost complete [Internet], CSPPLAZA, c2017, http://www.cspplaza.com/article-9397-1.html.

[43] China state Department of Environmental Protection, Environmental impact assessment report publicity: Environmental impact assessment report on 50MW molten salt LF-CSP project [Internet], China state Department of Environmental Protection, c2017, http://www.docin.com/p-1910872195.html.

[44] Hebei people's government, Thirteen projects with a total investment of 45 billion Yuan in Zhangbei were started at the same time [Internet], Hebei people's government., c2017, http://news.xinhuanet.com/local/2017-04/20/c_129555705.htm.

[45] CSPPLAZA. The first power generation test on the Conventional Island of Zhangjiakou 15MW CSP plant of Huaqiang Zhaoyang Energy Co. Ltd [Internet], CSPPLAZA, c2017, http:// www.cspplaza.com/article-9955-1.html.

[46] China state Department of Environmental Protection, Environmental impact assessment report on Inner Mongolia WuLate Middle Banner 50MW thermal oil LF-CSP project of Northern United Electric Power [Internet], China state Department of Environmental Protection, c2017, http://www.docin .com/p-1883226646.html.

[47] China National CSP industry technology innovation strategic alliance, Research Report on the CSP industry policy of China, Special report 3: Analysis for the incentive mechanism of solar thermal power industry in China [Internet], China National CSP industry technology innovation strategic alliance, c2015, https://wenku.baidu.com/view/84d14e9d4a7302768e9939b2 .html. 


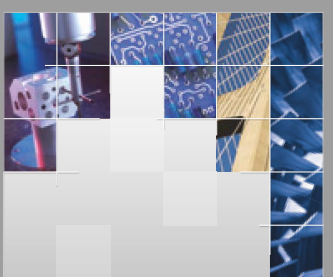

\section{Enfincering}
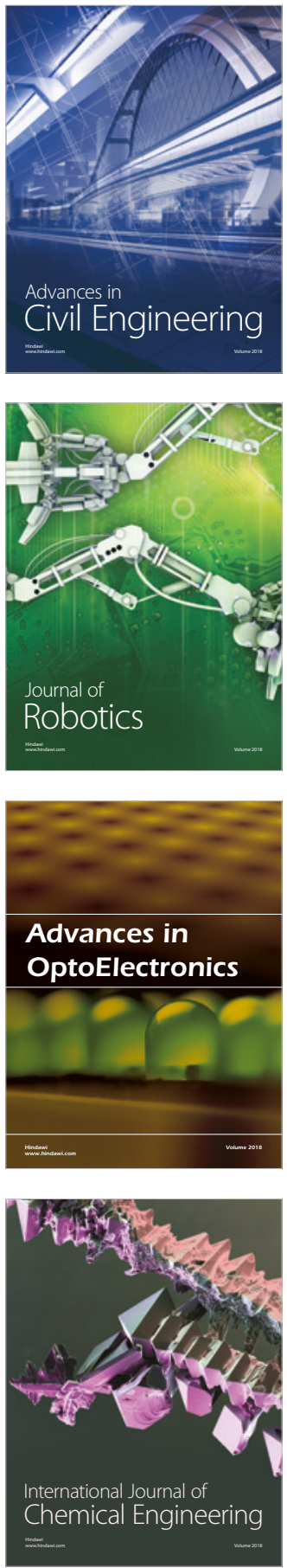

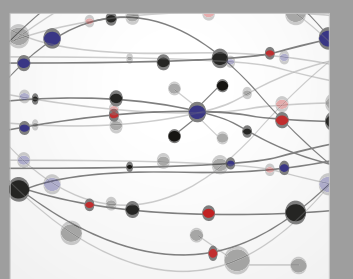

\section{Rotating \\ Machinery}

The Scientific World Journal

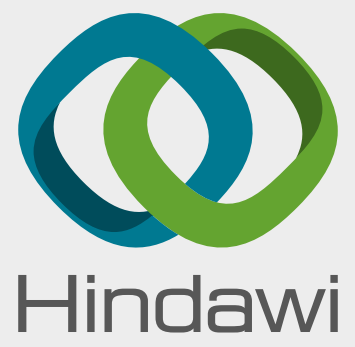

Submit your manuscripts at

www.hindawi.com
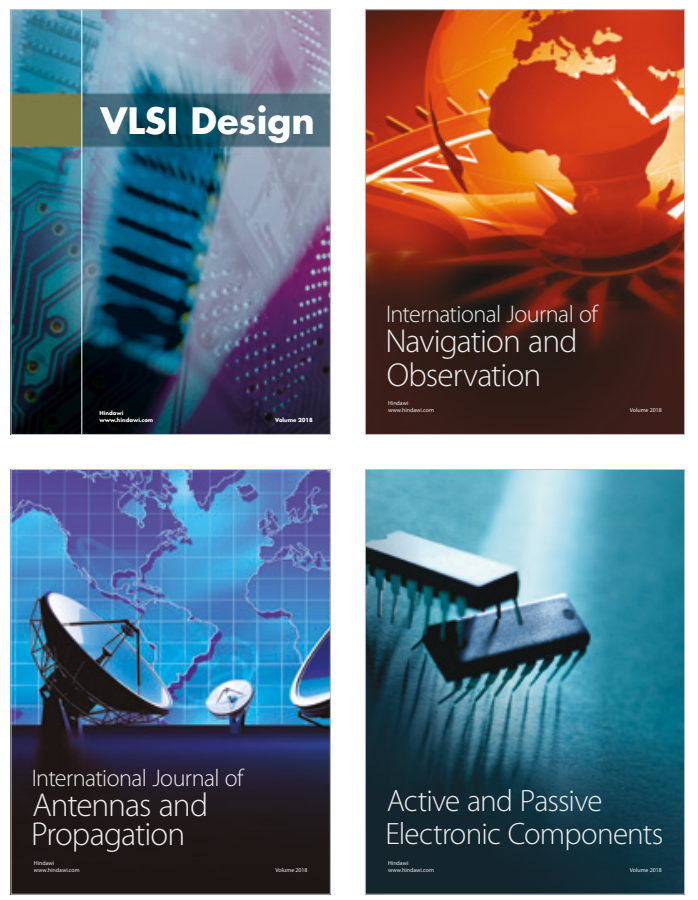
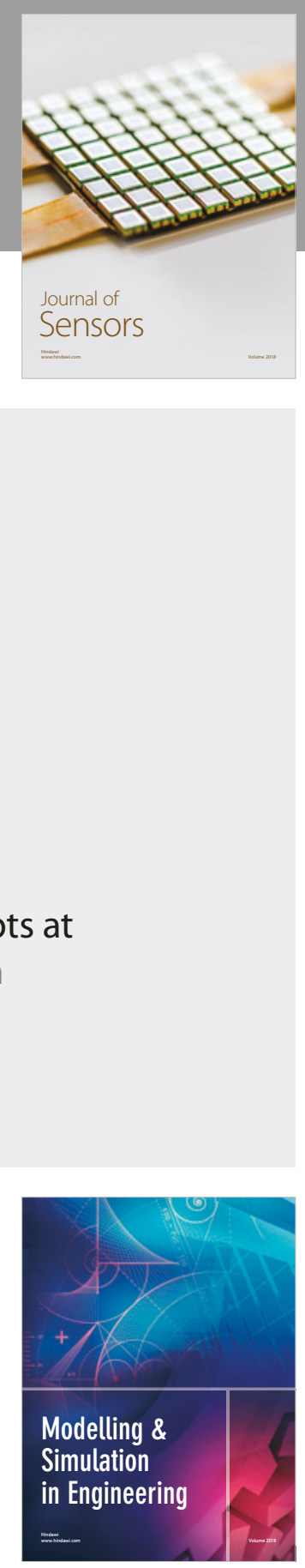

\section{Advances \\ Multimedia}
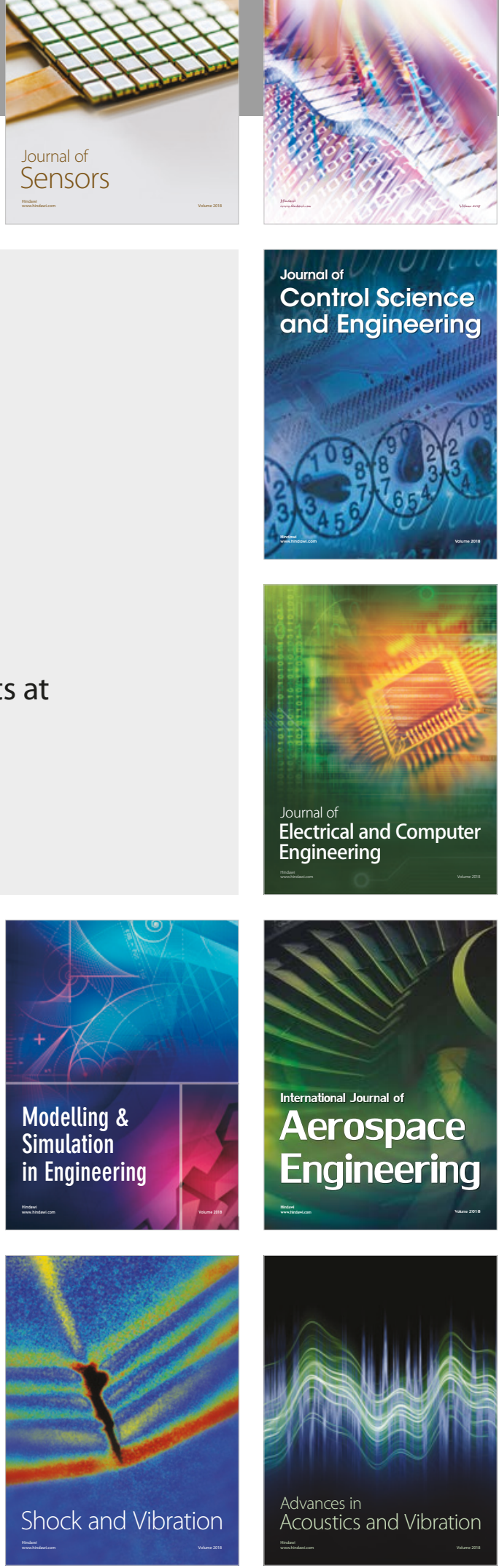